\title{
Phylogeography of the shanny Lipophrys pholis (Pisces: Blenniidae) in the NE Atlantic records signs of major expansion event older than the last glaciation
}

\author{
S.M. Francisco a,b,*, C. Faria a , W. Lengkeek ${ }^{c}$, M.N. Vieira ${ }^{\text {b }}$, E.M. Velasco ${ }^{\text {d }}$, V.C. Almada ${ }^{\text {a }}$ \\ a Eco-Ethology Research Unit, ISPA, Rua Jardim do Tabaco 34, 1149-041 Lisboa, Portugal \\ b Departamento de Biologia Animal, Faculdade de Ciências da Universidade do Porto, Rua do Campo Alegre, 4169-007 Porto, Portugal \\ c Marine Ecology Group, Bureau Waardenburg, Varkensmarkt 9, 4101 CK Culemborg, The Netherlands \\ d Instituto Español de Oceanografía, Centro Oceanográfico de Gijón Av Príncipe de Asturias 70, 33212 Gíjon, Spain
}

\section{A R T I C L E I N F O}

\section{Article history:}

Received 25 June 2010

Received in revised form 29 March 2011

Accepted 31 March 2011

Available online 8 May 2011

\section{Keywords:}

European marine fish

Evolutionary history

Patterns of genetic diversity in the NE Atlantic

Population genetics

Rock intertidal

\begin{abstract}
A B S T R A C T
The study of the phylogeography of inshore fish from West Europe is revealing diverse geographical and demographical patterns. Some species conform to the phylogeographic patterns typical of terrestrial organisms, with marked signatures of the last glaciation and a decline of genetic diversity to the north of the species range. Other species, however, reveal no decline in diversity with latitude and signatures of expansions older than the last glaciation. The shanny Lipophrys pholis is a common intertidal resident fish in west European rocky shores. It is unable to leave the rocky stretch where it settled as a juvenile, so that dispersal depends entirely on the planktonic larval stage. These life-history and behavioural traits make the shanny an interesting species for phylogeographical analysis, as long-range movements by adults, which could blur historical signals, are absent. In this paper the phylogeography of L. pholis was studied using a fragment of the mitochondrial control region and one from the first intron of the S7 ribosomal protein gene. The European samples (ranging from SW Spain to the Netherlands) did not display population differentiation, isolation-by-distance or latitudinal declines in genetic diversity. Iberia was proposed as having operated as the main glacial refugium for the shanny. The genealogy of the European population showed that the largest expansion detected was older than the last glaciation, with lineages persisting from the early Pleistocene, which does not conform to colonisation by a few founders in the current interglacial. It is argued that if fishes have very large population sizes and high dispersal rates, populations can efficiently track climatic shifts so that little or no genetic structure remains after each range expansion and latitudinal gradients of genetic diversity tend to be weak or non-existent.
\end{abstract}

(c) 2011 Elsevier B.V. All rights reserved.

\section{Introduction}

The North-eastern Atlantic and its adjacent water bodies (Mediterranean, North and Baltic Seas) are known to have suffered dramatic and periodic changes during the Pleistocene (Briggs, 1996). During the glacial peaks ice-cover and polar waters moved to much lower latitudes than those that prevail during interglacials such as the current one that has persisted since 10 thousand years ago (kya) (Climap Project Members, 1984). Thus, much of the northern and western European waters must have been periodically devoid of most temperate organisms with possible exception of a few unglaciated refugial locations (e.g. Mäkinen and Merilä, 2008). In the interglacials, temperate and especially warm-temperate organisms must have recolonised the west European shores from refugia in unglaciated areas (e.g. Gysels et al., 2004). Locations of these putative refugia have

\footnotetext{
* Corresponding author at: Eco-Ethology Research Unit, ISPA, Rua Jardim do Tabaco

34, 1149-041 Lisboa, Portugal. Tel.: +351 218811700; fax: +351 218860954.

E-mail address: sara_francisco@ispa.pt (S.M. Francisco).
}

been proposed in warmer parts of the Mediterranean (e.g. Domingues et al., 2005), to the south of the Iberian Peninsula (e.g. Francisco et al., 2009), and for cooler water species in unglaciated areas in northwest Iberia, southwest Ireland and the northern Britanny - Hurd Deep region of the English Channel, where a marine lake persisted during the Last Glacial Maximum (LGM - 18 kya) (e.g. Hoarau et al., 2007).

Phylogeographic histories of west European fish do not conform to a single pattern, with some species forming a single population (e.g. Petromyzon marinus in Almada et al., 2008; Thunnus thynnus in Bremer et al., 2005) and others displaying isolation-by-distance and/or clear population differentiation (e.g. Amblyraja radiate in Chevolot et al., 2006; and Atherina presbyter in Francisco et al., 2009). In some cases genetic diversity drops steeply to the extreme north of the species range (e.g. Pomatoschistus microps in Gysels et al., 2004), while in others it displays a similar level across the species distribution (e.g. Diplodus sargus in Domingues et al., 2007a,b). Finally, the genealogies obtained vary from very shallow (likely due to extreme bottlenecks and expansion after the last glaciation) (e.g. Almada et al., 2008) to ones that can be traced back to earlier phases of the Pleistocene (e.g. Sprattus sprattus in Debes et al., 2008). 
The shanny Lipophrys pholis (Linnaeus 1758) is a rocky intertidal fish, extremely common along the west European shores. It ranges from Norway to Mauritania and from the Azores and Madeira to the entrance of the Mediterranean [sporadic records which do not correspond to stable populations (Almada et al., 2001)]. The demersal eggs are guarded by the male and the larvae hatch ready to start exogenous feeding, living in the plankton for ca. 29 days at a temperature of $15.5-17.5^{\circ} \mathrm{C}$ (Faria et al., 2002). Juveniles and adults show restricted movements, and are thought to stay for life in the same rocky stretch (Faria et al., 1996). This life-history and behavioural trait makes the shanny an interesting species for phylogeographical analysis, as long-range movements by adults, which could blur historical signals, are absent.

A study by Stefanni et al. (2006) showed that fish from the Azores are sister to a group that included all fish from west Europe and the single specimen available from Madeira. These data also suggested that there is no genetic structure along west Europe, but both the number of individuals sequenced and the number of sampling locations were too few to allow a population genetic analysis (12 individuals in Portugal and two in Scotland). The only phylogeographic analysis (Francisco et al., 2006) failed to detect population differentiation along the Portuguese shore. The scope of this paper was, however, restricted to a few hundred kilometres and only mitochondrial DNA was analysed.

In the present paper, we extend the previous study in two ways: 1) we supplement the control region fragment with a nuclear one (the first intron of the S7 ribosomal protein gene) and 2) we extend the sampling coverage from near the entrance of the Mediterranean to the Netherlands, thus covering almost the entire range where the shanny is known to breed. The following questions where addressed: 1) Is there any phylogeographical structure in L. pholis along the European shore?; 2) How does the level of genetic diversity vary with latitude?; and 3) How old are the signatures of expansion/contraction events retained in the genealogies?

\section{Materials and methods}

\subsection{Sampling and DNA sequencing}

Specimens of $L$. pholis were collected from eight sites along the European Atlantic coast (Fig. 1, Table 1). Samples were collected in
Table 1

Diversity measures for the collecting sites of Lipophrys pholis for CR and S7: number of sequences $(\mathrm{N})$, number of haplotypes $\left(\mathrm{N}_{\mathrm{h}}\right)$, percentage of private haplotypes (\%Ph), number of polymorphic sites (S), haplotype diversity (h), nucleotide diversity $(\pi)$ and mean number of pairwise differences (PD).

\begin{tabular}{|c|c|c|c|c|c|c|c|c|}
\hline & Sampling site & $\mathrm{N}$ & $\mathrm{N}_{\mathrm{h}}$ & $\% \mathrm{Ph}$ & S & $\mathrm{h}$ & $\pi$ & PD \\
\hline \multirow[t]{9}{*}{ CR } & Total & 188 & 136 & $85 \%$ & 103 & 0.993 & 0.032 & 12.03 \\
\hline & Neeltje Jans & 19 & 19 & $79 \%$ & 43 & 1.000 & 0.028 & 10.61 \\
\hline & Carantec & 24 & 23 & $74 \%$ & 57 & 0.996 & 0.033 & 12.40 \\
\hline & Gijon & 20 & 17 & $56 \%$ & 40 & 0.984 & 0.030 & 11.39 \\
\hline & Camariñas & 21 & 18 & $67 \%$ & 42 & 0.981 & 0.029 & 10.88 \\
\hline & Cabo-do-Mundo & 27 & 24 & $75 \%$ & 51 & 0.992 & 0.033 & 12.49 \\
\hline & Estoril & 31 & 27 & $70 \%$ & 61 & 0.991 & 0.031 & 11.78 \\
\hline & Lagos & 31 & 26 & $58 \%$ & 52 & 0.989 & 0.031 & 11.95 \\
\hline & Cádiz & 15 & 15 & $73 \%$ & 37 & 1.000 & 0.028 & 10.59 \\
\hline \multirow[t]{9}{*}{ S7 } & Total & 314 & 26 & $58 \%$ & 25 & 0.663 & 0.005 & 1.58 \\
\hline & Neeltje Jans & 26 & 5 & $0 \%$ & 8 & 0.609 & 0.005 & 1.55 \\
\hline & Carantec & 36 & 5 & $0 \%$ & 8 & 0.582 & 0.005 & 1.43 \\
\hline & Gijon & 42 & 9 & $15 \%$ & 13 & 0.668 & 0.005 & 1.71 \\
\hline & Camariñas & 50 & 11 & $25 \%$ & 12 & 0.682 & 0.006 & 1.52 \\
\hline & Cabo-do-Mundo & 42 & 11 & $27 \%$ & 8 & 0.725 & 0.005 & 1.65 \\
\hline & Estoril & 40 & 8 & $13 \%$ & 6 & 0.668 & 0.005 & 1.61 \\
\hline & Lagos & 44 & 9 & $22 \%$ & 7 & 0.650 & 0.004 & 1.47 \\
\hline & Cádiz & 34 & 8 & $25 \%$ & 11 & 0.697 & 0.006 & 1.64 \\
\hline
\end{tabular}

rocky tide-pools and a small piece of dorsal fin was clipped and preserved in $96 \%$ ethanol.

Total genomic DNA extraction was performed with the REDExtract-N-mp kit (Sigma-Aldrich). The conditions for the amplifications were as follows: amplification in a $20 \mu \mathrm{l}$ volume containing approximately $20 \mathrm{ng}$ of genomic DNA extract, $0.3 \mu \mathrm{l}$ Taq DNA polymerase (Sogent F-taq), $2 \mu \mathrm{l}$ (10 pmol) of each primer, $3 \mu \mathrm{l}$ of buffer (supplied by the manufacturer) and $1 \mu \mathrm{l}(2.5 \mathrm{mM})$ of each dNTP. A fragment from the mitochondrial (mtDNA) control region (CR) was amplified using the primers L-pro1 (5' ACTCTCACCCCTAGCTCCCAAAG $3^{\prime}$ ) and H-DL1 (5' CCTGAAGTAGGAACCAGATGCCAG 3') (Ostellari et al., 1996). Polymerase Chain Reaction (PCR) was performed using the following profile: an initial denaturing step of; 35 cycles of denaturing at $95^{\circ} \mathrm{C}$ for $1^{\prime}$, annealing for $1^{\prime}$ at $58^{\circ} \mathrm{C}$, and extending at $72{ }^{\circ} \mathrm{C}$ for $1^{\prime}$ $30^{\prime \prime}$; a final extending step of $10^{\prime}$ at $72^{\circ} \mathrm{C}$. In addition, the first intron of the $\mathrm{S} 7$ ribosomal protein gene (S7) was amplified with the primers S7RPEX1F (5'-TGGCCTCTTCCTTGGCCGTC-3') and S7RPEX2R (5'AACTCGTCTGGC TTTTCGCC-3') (Chow and Hazama, 1998). The

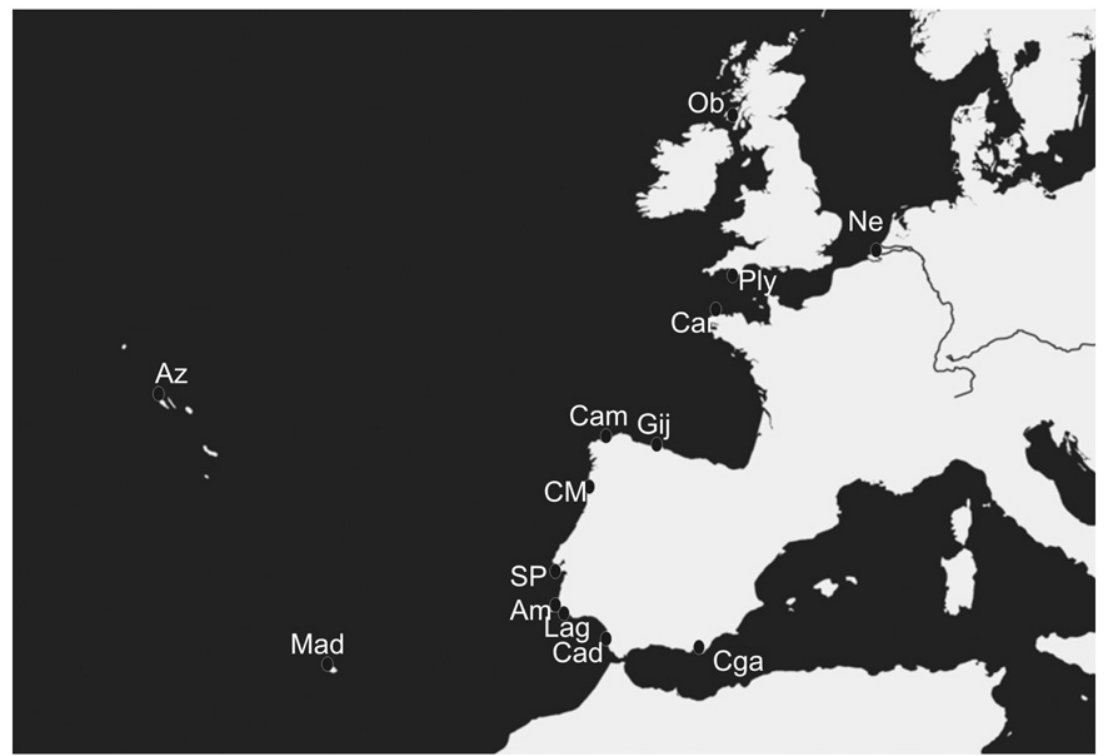

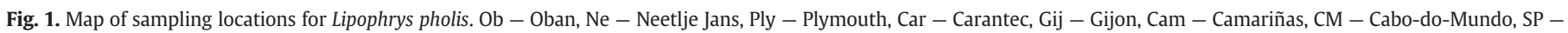
Estoril/Avencas, Am - Amoreira, Lag - Lagos, Cad - Cadiz, Cga - Cabo-da-Gata, and Mad - Madeira. 
amplification process was as follows: one step of $3^{\prime}$ at $95{ }^{\circ} \mathrm{C}, 35$ cycles of $\left[94{ }^{\circ} \mathrm{C}\right.$ for $45 \mathrm{~s}, 58{ }^{\circ} \mathrm{C}$ for $45 \mathrm{~s}$ and $72{ }^{\circ} \mathrm{C}$ for $1 \mathrm{~min}$ ], and a final extending step of $10^{\prime}$ at $72^{\circ} \mathrm{C}$. Purification and sequencing were performed as services by Macrogen (Seoul, Korea) and Stabvida (Oeiras, Portugal). Details on these procedures may be requested from the authors. Sequences obtained were deposited in GenBank (GU196686-784, GU301928-2243 and GU983860-1) and additional sequences were retrieved from a previous work: DQ154169-257 (Francisco et al., 2006) and AY966020-33 (Stefanni et al., 2006) (Table S1). The sequences were aligned with Clustal X2 (Larkin et al., 2007). For the S7 both strands of the same specimen were recovered following the approach of Sousa-Santos et al. (2005). This approach takes advantage of the presence of indels in a given nuclear marker, and uses them to accurately reconstruct the individual haplotypes without the need of probabilistic estimation.

\subsection{Phylogenetic and network analyses}

The software PAUP* 4.0b (Swofford, 2000) was used to construct Maximum-Parsimony (MP) using two sequences of Lipophrys trigloides as the outgroup (AY098860 and GU301926-27, for the CR and S7 respectively).

For both DNA fragments, haplotype networks were built with the software TCS 1.21 (Clement et al., 2000) using the parsimony method of Templeton et al. (1992). Due to the graphical complexity of the CR haplotype network, an additional network was constructed with a reduced dataset containing only transversions.

\subsection{Demographic analyses}

ARLEQUIN 3.11 (Excoffier et al., 2005) was used to estimate levels of genetic diversity, gene flow and population structure - by analysis of molecular variance AMOVA (Excoffier et al., 1992) and pairwise $\Phi_{\text {st. }}$. The correlation between geographic distance and $\Phi_{\text {st }}$ was computed with the Mantel test (Mantel, 1967; Smouse et al., 1986) (10,000 permutations; geographic distances measured along the shore line). The same software was used to test population expansion with Fu's Fs (Fu, 1997) and Tajima's $D$ (Tajima, 1989). In addition, the fit of the mismatch distribution to that expected under demographic expansion was also analysed (Rogers and Harpensding, 1992; Rogers, 1995). For S7, ARLEQUIN was also used to perform the linkage disequilibrium (LD) test and exact probability tests for deviations from the HardyWeinberg equilibrium (HWE).

A MCMC approach taking into account phylogenetic relationships among haplotypes as implemented in LAMARC 2.1.3 (Kuhner, 2006) was used to estimate effective population size $\left(\mathrm{N}_{\mathrm{ef}}\right)$ and the exponential growth parameter $(g)$ (details on runs may be requested from the authors). In order to compute estimates of effective population size, their changes with time, and the age of populations, we used two divergence rates for CR: 10\% (Bowen et al., 2006 between Centropyge lineages) and 3.6\% (Domingues et al., 2005 for the sister species Chromis chromis and C. limbata) and one for S7: 0.46\% (Bernardi and Lape, 2005 for Anisotremus taeniatus and A. verginicus, two transisthmian sister species of blennids separated 6.0-5.3 Mya before the closure of the isthmus of Panama). Values are divergence rates per million years and were halved to get an estimate of mutation rates per lineage per million years. Faria et al. (1996) reported that both sexes of L. pholis mature when they are one year old in the Portuguese coast, but Milton (1983), in Ireland, reported that maturation is achieved after a period of two years. Thus, a maturity period of two years was assumed bearing in mind that growth is going to be relatively slow during northerly populations and cooler climatic periods.

Past population dynamics of the shanny population were estimated with Extended Bayesian skyline plots (EBSP) (Heled and Drummond, 2006) using BEAST v.1.6 (Drummond and Rambaut, 2007). The EBSP generates a posterior distribution of $\mathrm{N}_{\mathrm{ef}}$ through time using a MCMC sampling. For both the $\mathrm{CR}$ and $\mathrm{S7}$ the MCMC analysis was run for $50 \times 10^{6}$ generations (sampled every 1000 iterations), of which the first $10 \%$ was discarded as burn-in ( 5 runs). The substitution models used were GTR $+\mathrm{G}$ for $\mathrm{CR}$ and $\mathrm{HKY}+\mathrm{G}$ for S7, respectively. For both markers, the time for most recent common ancestor ( $t_{\text {MRCA }}$ ) and the median and corresponding credibility intervals of the EBSP were depicted using Tracer v.1.4 (Rambaut and Drummond, 2007).

\section{Results}

For the CR a fragment of $380 \mathrm{bp}$ was amplified and the 188 sequences obtained define 136 haplotypes. A total of 103 polymorphic sites and 277 invariant positions were found. Differences among haplotypes corresponded to 102 transitions, 22 transversions and 2 indels. For the S7 the 314 sequences ( 157 individuals) define a total of 26 haplotypes. For this marker the fragment obtained was $646 \mathrm{bp}$ long, including 25 polymorphic sites and 621 invariant positions. Differences among haplotypes corresponded to 24 mutations (9 transitions, 8 transversions and 9 indels). From the 25 polymorphic sites found along the European coast two were clearly in heterozygote deficit, leading to a significant deviation from the HWE $(p<0.001)$. As for the LD test $13.67 \%$ of the possible loci pairs are in linkage disequilibrium, a relatively low value.

For both fragments, the genetic diversity indices showed little variation among collection sites and were generally high (Table 1). For the CR most haplotypes were private, with no consistent variation with latitude. Although Neeltje Jans is the most northern location, it is the one with the highest percentage of private haplotypes (79\%). For this fragment there were 20 shared haplotypes representing $15 \%$ of the total. The haplotype that spans the greatest latitudinal range was shared by three locations (Neeltje Jans, Lagos and Cádiz). The results were different for S7, as there were no private haplotypes for the sampling locations north of the Iberian Peninsula. In fact, for this fragment, the percentage of private haplotypes was significantly lower than for CR (Wilcoxon test $P<0.05$; overall: $58 \%$ vs $85 \%$ ). For $\mathrm{S7}$, 13 haplotypes were shared among the locations (50\% of total).

\subsection{Phylogenetic and network analyses}

For both markers the phylogenetic analyses failed to reveal any geographical structuring along the European shore (trees not shown).

All haplotypes for the $\mathrm{CR}$ of the shanny were linked together on a single Statistical Parsimony Network (SPN), under the confidence limit of 95\% (Templeton et al., 1992), with the exception of an haplotype from Estoril (SP17) (Fig. S1). A simplified SPN built only with transversions is shown in Fig. 2A. The network represents a deep genealogy with multiple levels of diversification, with some haplotypes reaching 10 mutational steps from the ancestral one (outgroup weight 0.0599 ). The ancestral haplotype gave rise to haplotypes found in all geographical areas (at one mutational step). Several haplotypes, including the ancestral one, are in the centre of star-like patterns that span one or two mutations from the respective centre, which could represent diversification processes after the last glaciation. These stars are wide spread geographically and, as stated above, represent only the most recent diversification events on a much deeper genealogy. It is interesting to note that the haplotype belonging to the only Mediterranean fish is very close to the ancestral one (Fig. 2A). For the S7 the SPN obtained is much less diverse (Fig. 2B), fact easily explained by the difference in mutation rate. Although simpler, this network also lacks geographical structure. It presents a star-like shape around the ancestral haplotype (outgroup weight 0.3711 ) but, even so, some of the branches reach a maximum of 10 mutational steps from the ancestor, which is consistent with the CR data about the likely persistence of several lineages in multiple glacial cycles. 

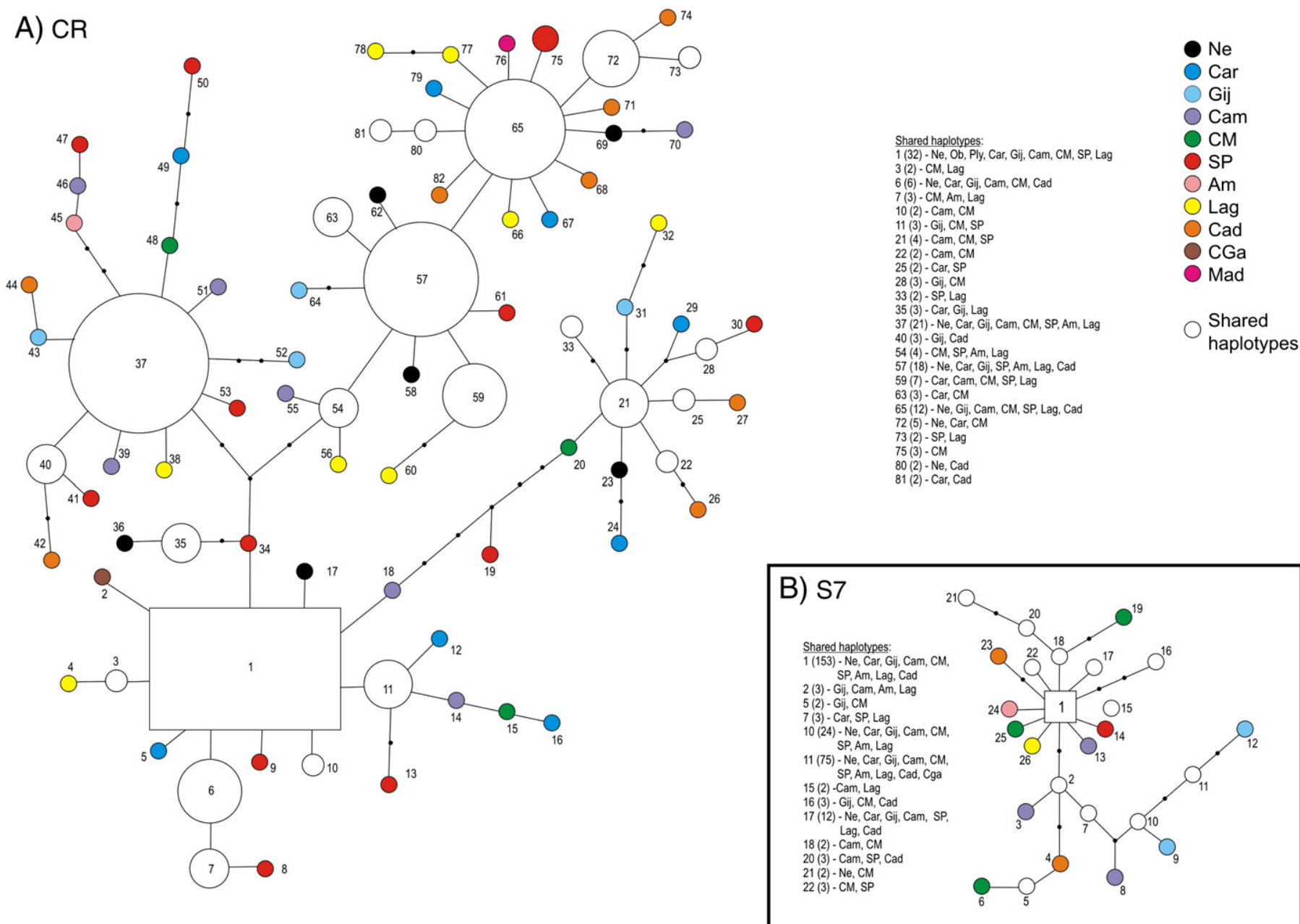

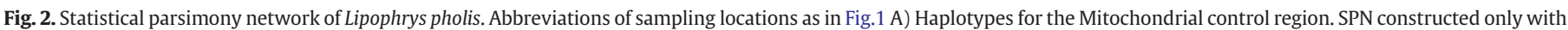
transversions B) Haplotypes for the first intron of the S7 ribosomal protein gene.

\subsection{Demographic analyses}

The AMOVA results computed for both markers did not reveal genetic structure along the European coast $\left(\mathrm{CR}: \mathrm{F}_{\mathrm{ST}}=0.011\right.$, $\left.P=0.102 ; \mathrm{S} 7: \mathrm{F}_{\mathrm{ST}}=-0.007, P=0.708\right)$. For the $\mathrm{CR}$ the number of migrants $(\mathrm{Nm})$ was always higher than 1 , and the values of $\Phi_{\mathrm{ST}}$ (Table 2) and Corrected Average Differences (Table S2) were not significant for the great majority of comparisons among collections sites. There were, however, some significant differences in both measurements with some comparisons involving Cadiz (pattern without geographical consistency). Considering the S7, no significant differences were found for the $\Phi_{\mathrm{ST}}$ (Table 2) and Corrected Average Differences (Table S2).

The Mantel Test does not support a correlation between the $\Phi_{\mathrm{st}}$ and geographical distances for both the CR and S7 of the shanny, with the coefficient of correlation itself being very close to zero $(r=0.023$ $P=0.342$ and $\mathrm{r}=-0.182 P=0.737$ respectively). Given the congruence of all the performed analyses, we decided to pool together the 8 sampling sites as a European population for further analysis.

Neutrality tests yielded negative values for both markers (Table 3); nevertheless, Fu's $F_{S}$ for the $C R$ is the only significant value, suggesting demographic expansion.

The analyses of the mismatch distributions for CR and S7 did not differ significantly from the model of sudden expansion for the European population (Table 3, Fig. 3). For the CR (Fig. 3A) we can detect a stronger peak at 15 differences and another one around 3. With this marker the estimates point to an age of population between
400 Kya and 1 mya, and thus would not be the consequence of the last two glaciations. The S7 graph (Fig. 3B) also revealed several peaks, with the highest being in the 7 differences. Even when we use this

Table 2

Geneflow among collecting sites of Lipophrys pholis represented by Nm (above diagonal) and $\Phi_{\mathrm{ST}}$ (bellow diagonal), and based on the Tamura-Nei model. Significant values of probability $P$ are shown with an *. Cad - Cádiz, Lag - Lagos, SP - Estoril, CM Cabo-do-Mudo, Cam - Camariñas, Gij - Gijon, Car - Carantec, and Ne - Neeltje Jans. Inf - Infinite.

\begin{tabular}{|c|c|c|c|c|c|c|c|c|}
\hline & Cad & Lag & SP & $\mathrm{CM}$ & Cam & Gij & Car & $\mathrm{Ne}$ \\
\hline \multicolumn{9}{|l|}{$C R$} \\
\hline Cad & & 7.352 & 3.936 & 14.366 & 3.027 & 3.452 & 5.640 & 23.168 \\
\hline Lag & $0.064^{*}$ & & $\inf$ & inf & 313.617 & $\inf$ & $\inf$ & inf \\
\hline SP & $0.113^{*}$ & -0.010 & & 80.849 & inf & inf & inf & 41.197 \\
\hline $\mathrm{CM}$ & 0.034 & -0.004 & 0.006 & & 105.949 & 73.097 & inf & 244.591 \\
\hline Cam & $0.142^{*}$ & 0.002 & -0.026 & 0.005 & & $\inf$ & inf & 14.601 \\
\hline Gij & $0.126^{*}$ & -0.005 & -0.015 & 0.007 & -0.026 & & inf & 12.680 \\
\hline Car & $0.081^{*}$ & -0.013 & -0.025 & -0.004 & -0.018 & -0.013 & & inf \\
\hline $\mathrm{Ne}$ & 0.021 & -0.003 & 0.012 & 0.002 & 0.033 & 0.038 & -0.007 & \\
\hline \multicolumn{9}{|l|}{$S 7$} \\
\hline Cad & & 9.950 & 135.075 & 21.877 & 60.954 & inf & 11.391 & inf \\
\hline Lag & 0.048 & & inf & inf & inf & 90.043 & inf & inf \\
\hline SP & 0.004 & -0.012 & & inf & inf & inf & inf & inf \\
\hline $\mathrm{CM}$ & 0.022 & -0.013 & -0.017 & & inf & inf & inf & inf \\
\hline Cam & 0.008 & -0.012 & -0.022 & -0.016 & & inf & inf & inf \\
\hline Gij & -0.010 & 0.006 & -0.017 & -0.007 & -0.014 & & 418.601 & inf \\
\hline Car & 0.042 & -0.024 & -0.017 & -0.014 & -0.015 & 0.001 & & inf \\
\hline $\mathrm{Ne}$ & -0.012 & -0.011 & -0.030 & -0.019 & -0.026 & -0.028 & -0.015 & \\
\hline
\end{tabular}


Table 3

Demographic parameters of Lipophrys pholis based CR and S7. Significant values of probability $P$ are shown with an *. Neutrality tests: Fs (Fu's), $D$ (Tajima's). Mismatch distributions: $\tau$ (time in generations; upper and lower bounds of $95 \% \mathrm{CI}$ in parenthesis), $\mathrm{t}$ (time in years), $\theta_{0}$ (theta 0 ), $\mathrm{N}_{0}$ (female effective population size before the expansion), $\theta_{1}$ (theta1), $N_{1}$ (female effective population size after the expansion), SSD (sum of square deviation) and Hri (Harpending's Raggedness index). Estimates of population parameters with LAMARC: $\theta$ (theta), $\mathrm{N}_{\mathrm{f}}$ (female effective population size), $g$ (growth rate), and $\mathrm{N}_{1 \%}$ (age of population, accessed as the age at which $\mathrm{N}_{\mathrm{f}}$ drops below $1 \%$ ). Estimates of $t_{\text {MRCA }}$ (time to most recent common ancestor) with BEAST.

\begin{tabular}{lll}
\hline Population & Europe & $\mathrm{S} 7$ \\
\cline { 2 - 3 } & $\mathrm{CR}$ & -5.491 \\
\hline$F_{\mathrm{s}}$ & $-24.040^{*}$ & -1.043 \\
$D$ & -1.136 & \\
& & 7.607 \\
Mismatch distribution & & $(0.291-57.273)$ \\
$\tau(95 \% \mathrm{CI})$ & 14.764 & $256 \mathrm{ky}$ \\
$\mathrm{t}(95 \% \mathrm{CI})$ & $(9.705-18.082)$ & $(10 / 1,927)$ \\
& $388 / 1,079 \mathrm{ky}$ & 0.002 \\
$\theta_{0}$ & $(255 / 709-476 / 1,322)$ & 34 \\
$\mathrm{~N}_{0}$ & 0.004 & 3.556 \\
$\theta_{1}$ & $105 / 292$ & 110,093 \\
$\mathrm{~N}_{1}$ & 56.387 & 0.081 \\
$\mathrm{SSD}$ & $1,482,868 / 4,121,857$ & 0.182 \\
Hri & 0.007 & \\
& 0.005 & 0.0007 \\
Lamarc & & 15,967 \\
$\theta$ (no growth) & & - \\
$\mathrm{N}_{\mathrm{f}}$ (no growth) & 0.0899 & - \\
$\theta$ (with growth) & $899,374 / 2,498,261$ & - \\
$\mathrm{N}_{\mathrm{f}}$ (with growth) & 0.2227 & - \\
$\mathrm{g}$ & $2,227,287 / 6,186,908$ & \\
$\mathrm{~N}_{1 \%}$ & 147.262 & $\mathrm{ky}$ \\
Beast & $625 / 1,737 \mathrm{ky}$ & \\
$t_{\mathrm{MRCA}}$ & & \\
\hline
\end{tabular}

marker with a much slower mutation rate, the age of the European population last expansion (84-98 kya) is older than the LGM. For both markers $\mathrm{N}_{0}$ was unequivocally greater than zero.

The demographic parameters estimated with Lamarc for the $C R$ are also shown in Table 3. The corresponding analysis for S7 did not reach stability and was discarded. The confidence intervals of the age of L. pholis population globally overlap with the previous analysis (625 kya-1,7 mya).

The results from the Bayesian skyline plot analyses are summarised in Fig. 4. For the CR data, according to the plot (Fig. 4A) the shanny population experienced a faster population growth around 60 ky before present. The skyline plot for S7 (Fig. 4B) identifies a moderate effective population size reduction between $~ 120-100$ kya reaching a minimum of 600 individuals. A strong ( 7 -fold) and rapid size expansion began at $\sim 80$ kya. It is noteworthy that time of the population reduction does not correlate with the LGM, and the expansion dates are not in agreement with the end of the LGM, corroborating the previous analyses. Both markers yielded congruent estimates for the $t_{\text {MRCA: }} \sim 1$ My (Table 3).

\section{Discussion}

The present results raise at least two different issues: 1) the lack of a detectable decline of genetic diversity in the north of the species range and the homogeneity of the population along a large stretch of European coast; and 2) the complexity and depth of the genealogies found. We will address them in turn.

\subsection{Homogeneity of the European population}

The failure to detect strong fragmentation among European locations and the lack of support for a model of IBD lead us to assume that the west European samples may be viewed as belonging to a
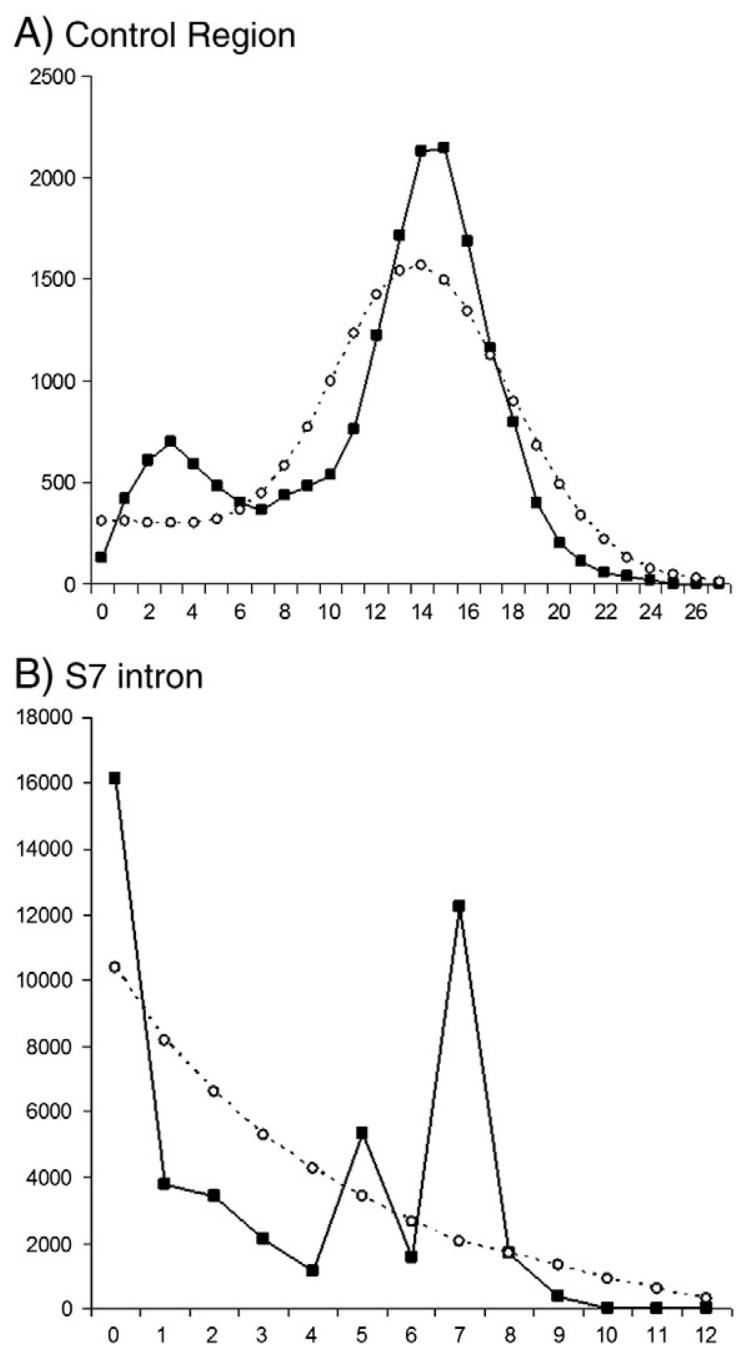

Fig. 3. Mismatch distributions for the European population of Lipophrys pholis A) Mitochondrial control region. B) First intron of the S7 ribosomal protein gene.

single population. It is interesting to note that there is no decline of genetic diversity with latitude.

In glacial peaks like the LGM, much of the North Sea was icecovered and the waters north of Bay of Biscay were polar to sub-polar (Climap Project Members, 1984). Judging from the present distribution of $L$. pholis, it is unlikely that it kept viable populations north of Spain. In the meantime, habitats may have become available to the south, along northwest Africa and possibly in the Mediterranean. Indeed, the absence of stable populations in the present day Mediterranean may represent local extinction after the last glacial period, as the fish do not seem to be able to breed at temperatures higher than $17^{\circ} \mathrm{C}$ (Almada et al., 1990). The waters around Iberia would be adequate for the survival of the species and it seems reasonable to assume that Iberia must have played an important role as a refugium from which the shanny recolonised West Europe when sea temperature rose in the last 10 thousand years (ky) [according to Climap Project Members (1984) the west Iberian coast yielded water temperatures of $7.2^{\circ} \mathrm{C}$, figures comparable to the present day SST in the North Sea]. If one considers a dispersal of $10 \mathrm{~km}$ in the same direction per generation (which is a moderate estimate for marine organisms with planktonic larvae) (Cowen and Sponaugle, 2009), $10 \mathrm{ky}$ would have ensured the recolonisation of the northern waters and would allow the northwards transport of much of the species genetic diversity. If the scenario depicted above is correct, time to disperse from a south-western refugium is not the limiting factor for 
A)

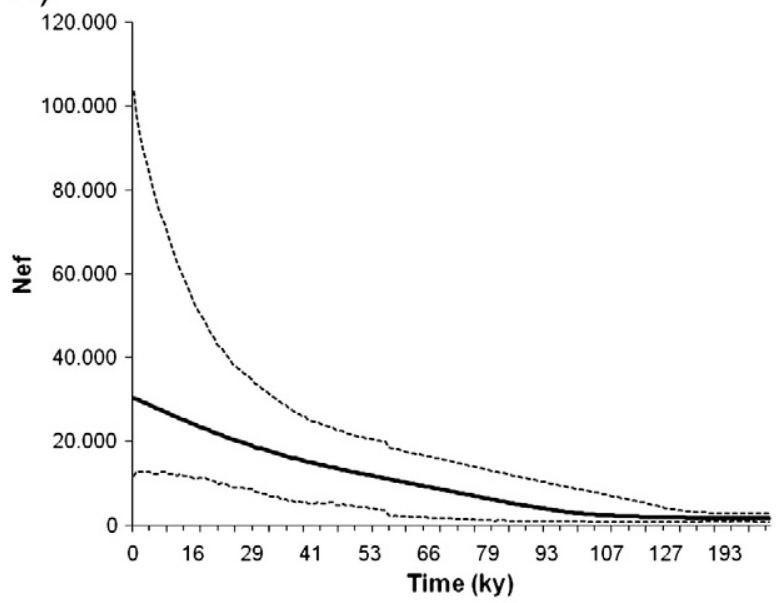

B)

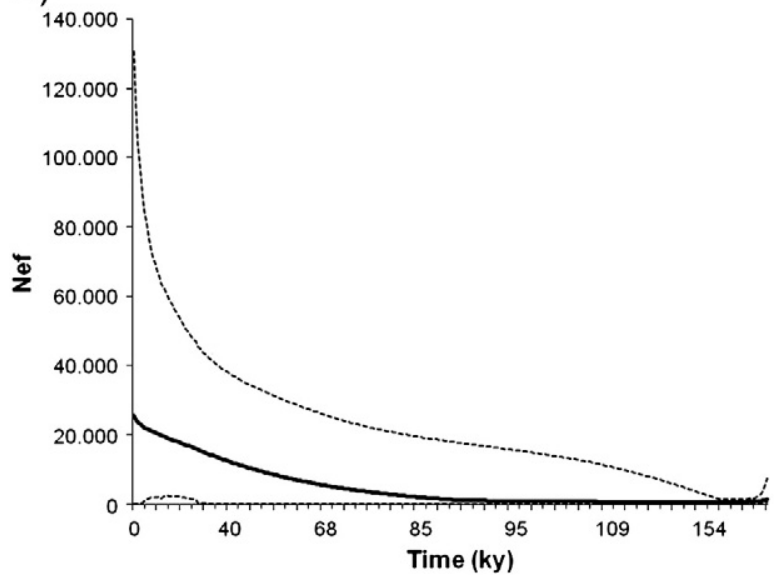

Fig. 4. Extended Bayesian skyline plot for the European population of Lipophrys pholis. The solid line indicates the median estimate, whereas the dotted lines indicate the $95 \%$ credibility intervals. A) Mitochondrial control region. B) First intron of the S7 ribosomal protein gene. $\mathrm{N}_{\mathrm{ef}}-$ female effective population size.

inshore benthic fish with planktonic larvae to recolonise west Europe after a glaciation. Rather, the oceanographic conditions prevailing during the breeding season and the behaviour and ecology from both larvae and adults will affect the colonisation process and the level of population differentiation.

\subsection{The complexity and depth of the genealogies}

All lines of available evidence point to the conclusion that the main expansion event recorded in the mismatch distribution occurred after an earlier glaciation which apparently affected the population more severely than the most recent glacial maximum. While the smaller peak (three differences) in the mismatch distributions of the CR may correspond to an expansion after the LGM, the largest peak corresponds to 15 differences. Some lineages must even be older than that event, reaching 27 differences. The dates estimated with both markers are consistently older than the LGM. The Bayesian skyline plots provide evidence for the main population expansions to have occurred during the Würm glacial cycle (12-110 kya; van Husen, 2004). Finally, the values of $\mathrm{N}_{0}$ are well above zero, indicating that the expansions began from a population that was not subjected to a drastic bottleneck. Several studies on European coastal organisms also showed past expansion events clearly older than the LGM: A. presbyter (Francisco et al., 2009), Pomatoschistus minutus (Larmuseau et al., 2009), Fucus serratus (Hoarau et al., 2007), Pollicipes pollicipes (Campo et al., 2010), etc. This holds even for organisms that seem to have been able to invade the North Sea after the last glaciation (e.g. A. presbyter in Francisco et al., 2009; S. sprattus in Debes et al., 2008). This is not a generalised result and past expansion associated with the LGM has also been found in some marine organisms (e.g. Coryphoblennius galerita in Domingues et al., 2007a,b; Necora puber in Sotelo et al., 2009; Palinurus elephas in Palero et al., 2008).

The haplotype network of the CR (Fig. 2a) includes a number of stars of haplotypes at the tips of the branches of an older and complex diversification process. Taken together, all analyses point to a population which retained substantial genetic diversity between glacial cycles and may coalesce after a genealogical history extending to the middle or early Pleistocene. Several studies of temperate marine fishes and other organisms show that the North-eastern Atlantic frequently lacks strong phylogeographical structure, while the genealogies extend well behind the last glaciation (e.g. Debes et al., 2008).

We suggest that the populations of many marine organisms may move up and down the west European shore with the glacial cycles retaining much of their genetic diversity, although undergoing reductions and expansions in each glacial cycle. This will be especially true for species with large population sizes and dispersal rates that are sufficiently high to enable them to track climate changes efficiently, by shifting their ranges. In such cases, a reduction of a very large population may still leave a large enough sample to retain much of the previous genetic diversity during population size decreases.

Supplementary materials related to this article can be found online at doi: 10.1016/j.jembe.2011.03.020.

\section{Acknowledgments}

We acknowledge a grant to S.M.F. (SFRH/BD/12653/2003) from FCT. The UIE-ISPA is funded by FCT through the pluri-annual and programmatic funding scheme (FEDER) as research unit \#331/94. This work was also funded by MARIN-ERA/MAR/0001/2008. The authors are grateful to $\mathrm{S}$. Chenu for her help with the laboratory work. [RH]

\section{References}

Almada, V.C., Barata, E.N., Gonçalves, E.J., Oliveira, R.F., 1990. On the breeding season of Lipophrys pholis (Pisces: Blenniidae) at Arrábida. Portugal. J. Mar. Biol. Assoc. U. K. 70, 913-916.

Almada, V.C., Oliveira, R.F., Gonçalves, E.J., Almeida, A.J., Santos, R.S., Wirtz, P., 2001. Patterns of diversity of the north-eastern Atlantic blenniid fish fauna (Pisces: Blenniidae). Glob. Ecol. Biogeograph. 10, 411-422.

Almada, V.C., Pereira, A.M., Robalo, J.I., Fonseca, J.P., Levy, A., Maia, C., Valente, A., 2008. Mitochondrial DNA fails to reveal genetic structure in sea-lampreys along European shores. Mol. Phylogenet. Evol. 46, 391-396.

Bernardi, G., Lape, J., 2005. Tempo and mode of speciation in the Baja California disjunct fish species Anisotremus davidsonii. Mol. Ecol. 14, 4085-4096.

Bowen, B.W., Muss, A., Rocha, L., Grant, W.S., 2006. Shallow mtDNA coalescence in Atlantic pygmy angelfishes (genus Centropyge) indicates a recent invasion from the Indian Ocean. J. Hered. 97, 1-12.

Bremer, J.R.A., Viñas, J., Mejuto, J., Ely, B., Pla, C., 2005. Comparative phylogeography of Atlantic blue fin tuna and swordfish: the combined effects of vicariance, secondary contact, introgression, and population expansion on the regional phylogenies of two highly migratory pelagic fishes. Mol. Phylogenet. Evol. 36, 169-187.

Briggs, J.V., 1996. Global Biogeography. Developments in paleontology and stratigraphy, vol.14. Elsevier, Amsterdam.

Campo, D., Molares, J., Garcia, L., Fernandez-Rueda, P., Garcia-Gonzalez, C., GarciaVazquez, E., 2010. Phylogeography of the European stalked barnacle (Pollicipes pollicipes): identification of glacial refugia.

Chevolot, M., Wolfs, P.H.J., Pálsoon, J., Rijnsdorp, A.D., Stam, W.T., Olsen, J.L., 2006. Population structure and historical demography of the thorny skate (Amblyraja radiate, Rajidae) in North Atlantic. Mar. Biol. 151, 1275-1286.

Chow, S., Hazama, K., 1998. Universal PCR primers for S7 ribosomal protein gene introns in fish. Mol. Ecol. 7, 1247-1263.

Clement, M., Posada, D., Crandall, K.A., 2000. TCS: a computer program to estimate gene genealogies. Mol. Ecol. 9, 1657-1660.

Climap Project Members, 1984. The last interglacial ocean. Quat. Res. 21, 123-224.

Cowen, R.K., Sponaugle, S., 2009. Larval dispersal and marine population connectivity. Ann. Rev. Mar. Sci. 1, 443-466.

Debes, P.V., Zachos, F.E., Hanel, R., 2008. Mitochondrial phylogeography of the European sprat (Sprattus sprattus L., Clupeidae) reveals isolated climatically vulnerable populations in the Mediterranean Sea and range expansion in the northeast Atlantic. Mol. Ecol. 17, 3873-3888. 
Domingues, V.S., Bucciarelli, G., Almada, V.C., Bernardi, G., 2005. Historical colonization and demography of the Mediterranean damselfish Chromis chromis. Mol. Ecol. 13, 4051-4063.

Domingues, V.S., Faria, C., Stefanni, S., Satos, R.S., Brito, A., Almada, V.C., 2007a. Genetic divergence in the Atalntic Mediterranean Montagu's blenny Coryphoblennius galerita (Linnaeus 1758) revealed by molecular and morphological characters. Mol. Ecol. 16, 3592-3605.

Domingues, V.S., Santos, R.S., Brito, A., Alexandrou, M., Almada, V.C., 2007b. Mitochondrial and nuclear markers reveal isolation-by-distance and effects of Pleistocene glaciations in the north-eastern Atlantic and Mediterranean populations of the white seabream (Diplodus sargus, L.). J. Exp. Mar. Biol. Ecol. 346, 102-113.

Drummond, A.J., Rambaut, A., 2007. BEAST: Bayesian evolutionary analysis by sampling trees. BMC Evol. Biol. 7, 214.

Excoffier, L., Smouse, P.E., Quattro, J.M., 1992. Analysis of molecular variance inferred from metric distances among DNA haplotypes: application to human mitochondrial DNA restriction data. Genetics 131, 479-491.

Excoffier, L., Laval, G., Schneider, S., 2005. Arlequin ver 3.0: An integrated software package for population genetics data analysis. Evol. Bioinform. Online 1, 47-50.

Faria, C., Almada, V.C., Gonçalves, E.J., 1996. Juvenile recruitment, growth and maturation of Lipophrys pholis (Pisces: Blenniidae), from the west coast of Portugal. J. Fish Biol. 49, 727-730.

Faria, C., Borges, R., Gil, F., Almada, V.C., Gonçalves, E.J., 2002. Embryonic and larval development of Lipophrys pholis (Pisces: Blenniidae). Sci. Mar. 66, 21-26.

Francisco, S.M., Vieira, M.N., Almada, V.C., 2006. Genetic structure and historical demography of the shanny Lipophrys pholis in the Portuguese coast based on mitochondrial DNA analysis. Mol. Phylogenet. Evol. 39, 288-292.

Francisco, S.M., Castilho, R., Soares, M., Congiu, L., Brito, A., Vieira, M.N., Almada, V.C., 2009. Phylogeography and demographic history of Atherina presbyter (Pisces: Atherinidae) in the North-eastern Atlantic based on mitochondrial DNA. Mar. Biol. 156, 1421-1432.

Fu, Y.X., 1997. Statistical tests of neutrality of mutations against population growth, hitchhiking and background selection. Genetics 147, 915-925.

Gysels, E.S., Hellemans, B., Pampoulie, C., Volckaert, A.M., 2004. Phylogeography of the common goby, Pomatoschistus microps, with particular emphasis on the colonization of the Mediterranean and the North Sea. Mol. Ecol. 13, 403-417.

Heled, J., Drummond, A.J., 2006. Bayesian inferecence of population size history from multiple loci. BMC Evol. Biol. 8, 289.

Hoarau, G., Coyer, J.A., Veldsink, J.H., Stam, W.T., Olsen, J.L., 2007. Glacial refugia and recolonization pathways in the brown seaweed Fucus serratus. Mol. Ecol. 16, 3606-3616.

Kuhner, M.K., 2006. LAMARC 2.0: Maximum likelihood and Bayesian estimations of population parameters. Bioinformatics 22, 768-770.

Larkin, M.A., Blackshields, G., Brown, N.P., Chenna, R., McGettigan, P.A., McWilliam, H., Valentin, F., Wallace, I.M., Wilm, A., Lopez, R., Thompson, J.D., Gibson, T.J., Higgins, D.G., 2007. Clustal W and Clustal X version 2.0. Bioinformatics 23, 2947-2948.
Larmuseau, M.H.D., Van Houdt, J.K.J., Guelinckx, J., Hellemans, B., Volckaert, F.A.M., 2009. Distributional and demographic consequences of Pleistocene climate fluctuations for a marine demersal fish in the north-eastern Atlantic. J. Biogeo. 36, 1138-1151.

Mäkinen, H.S., Merilä, J., 2008. Mitochondrial DNA phylogeography of the three-spined stickleback (Gasterosteus aculeatus) in Europe - Evidence for multiple glacial refugia. Mol. Phylogenet. Evol. 46, 167-182.

Mantel, N., 1967. The detection of disease clustering and a generalized regression approach. Cancer Res. 27, 209-220.

Milton, P., 1983. Biology of littoral blenniid fishes on the coast of South-West England. Symp. Zool. Soc. Lond. 44, 263-306.

Ostellari, L., Barglloni, L., Penzo, E., Patarnello, P., Patarnello, T., 1996. Optimization of single-strand conformation polymorphism and sequence analysis of the mitochondrial control region in Pagellus bogaraveo (Sparidae, Teleostei): rationalized tools in fish population biology. Anim. Genet. 27, 423-427.

Palero, F., Abelló, P., Macpherson, E., Gristina, M., Pascual, M., 2008. Phylogeography of the European spiny lobster (Palinurus elephas): influence of current oceanographical features and historical processes. Mol. Phylogen. Evol. 48, 708-717.

Rambaut, A., Drummond, A.J., 2007. Tracer [computer program]. http://tree.bio.ed.ac.uk/ software/tracer/.

Rogers, A.R., 1995. Genetic evidence for a Pleistocene population explosion. Evolution 49, 608-615.

Rogers, A.R., Harpensding, H., 1992. Population growth makes waves in the distribution of pairwise genetic differences. Mol. Biol. Evol. 9, 552-569.

Smouse, P.E., Long, J.C., Sokal, R.R., 1986. Multiple regression and correlation extensions of the Mantel Test of matrix correspondence. Syst. Zool. 35, 627-632.

Sotelo, G., Posada, D., Morán, P., 2009. Low-mitochondrial diversity and lack of structure in the velvet swimming crab Necora puber along the Galician coast. Mar Biol 156 1039-1048.

Sousa-Santos, C., Robalo, J.I., Collares-Pereira, M.J., Almada, V.C., 2005. Heterozygous indels as useful tools in the reconstruction of DNA sequences and in assessment of ploidy level and genomic constitution of hybrid organisms. DNA Seq. 16, 462-467.

Stefanni, S., Domingues, V., Bouton, N., Santos, R.S., Almada, F., Almada, V., 2006 Phylogeny of the shanny, Lipophrys pholis, from the NE Atlantic using mitochondrial DNA markers. Mol. Phylogenet. Evol. 39, 282-287.

Swofford, D.L., 2000. PAUP* Phylogenetic Analysis Using Parsimony (*and other methods), Version 4. Sinauer Associates Inc, Sunderland, MA, USA.

Tajima, F., 1989. The effect of change in population size on DNA polymorphism. Genetics 123, 597-660.

Templeton, A.R., Crandall, K.A., Sing, C.F., 1992. A cladistic-analysis of phenotypic associations with haplotypes inferred from restriction endonuclease mapping and DNA-sequence data. III. Cladogram estimation. Genetics 132, 619-633.

Van Husen, D., 2004. Quaternary glaciations in Austria. In: Ehlers, J., Gibbard, P.L. (Eds.), Quaternary glaciations - Extent and Chronology. Part I. Elsevier, Europe, pp. 1-14. 